V. Chenchevoi, Iu. Romashykhin, Zh. Romashykhina, Atef S. Al-Mashakbeh

\title{
ANALYSIS OF THE SPECIAL FEATURES OF THE THERMAL PROCESS IN AN INDUCTION GENERATOR AT HIGH SATURATION OF THE MAGNETIC SYSTEM
}

\begin{abstract}
Purpose. Development of the method for the assessment of the thermal operation modes of an autonomous electrical power system with an induction motor, aiming at improvement of the reliability of electricity supply and the quality of electric energy. Methodology. Induction generator mathematical modeling taking into account the magnetic system saturation was used in the research. A heat model taking into account the excess of the temperature of the induction generator units in the mode of high saturation was developed. The obtained results were compared with the experimental data. Results. The paper contains the solution to the problem of improvement of the mathematical model sand methods for steel losses determination in there search of the operation modes of an autonomous uncontrolled induction generator taking into consideration the properties of the magnetic system in the mode of high saturation. The expression for determination of steel losses in the mode of high saturation is obtained. It enables the assessment of the induction generator thermal condition. Originality. The analytical dependence for the calculation of the steel losses in the mode of magnetic system saturation has been obtained for the first time. Practical value. The obtained expression for the calculation of the steel losses can be used for determination of the admissible time of generator operation at overload. It will allow avoiding broken winding insulation and complete use of the generator overload capacity. As a result, it will reduce possible irregularities of electricity supply due to the generator preliminary cutoff. References 10, tables 2, figures 3 .

Key words: autonomous induction generator, magnetic system saturation, steel losses, thermal processes.
\end{abstract}

Цель. Разработка методики оценки тепловых режимов работы автономной электроэнергетической системы с асинхронным генератором с целью повышения надежности электроснабжения и качества электроэнергии. Методология. Для проведения исследований использовалось математическое моделирование асинхронного генератора с учетом насыщения магнитной системы. Разработана тепловая модель, которая учитывает превышение температуры узлов асинхронного генератора в режиме высокого насыщения. Полученные результаты моделирования сравнивались с экспериментальными данными. Результаты. В работе решена задача усовершенствования математических моделей и методов определения потерь в стали при исследовании режсимов работы автономного нерегулируемого асинхронного генератора с учетом свойств магнитной системы в режиме высокого насыщения. Получено выражение для определения потерь в стали в режиме высокого насыщения, которое позволяет оценивать тепловое состояние асинхронного генератора. Оригинальность. Виервые получена аналитическая зависимость для расчета потерь в стали в режсме насыщения магнитной системы. Практическое значение. Полученное выраэсние для расчета потерь в стали может быть использовано для определения допустимого времени работы генератора при перегрузке. Это позволит избежсать повреждения изоляции обмоток и в полном объеме использовать перегрузочную способность генератора. В результате это снизит возможные перебои с электрической энергией из-за преждевременного отключения генератора. Библ. 10, табл. 2 , рис. 3.

Ключевые слова: автономный асинхронный генератор, насыщение магнитной системы, потери в стали, тепловые процессы.

Introduction. Autonomous electrical power systems (AES) take an important place in the development of power engineering [1]. Recently AES have become widespread in electricity supply systems of both special and general purpose. The domain of application of such systems includes electric devices (stationary, mobile ones), controlled electromechanical systems (transport, small hydroelectric stations, wind energy plants), no-break power systems of important consumers. The necessity for the use of AES occurs when it is technically impossible or economically unprofitable to apply centralized electricity supply.

AES theoretical research and practical experience of their application show that there are good prospects of the use of induction generators (IG) with capacitor excitation as a power supply in them.

In spite of availability of a great number of papers related to theoretical and practical research of AES with IG the problems of these systems have not been completely solved. In particular, the thermal transient processes in IG with capacitor self-excitation at high saturation of the magnetic system are insufficiently analyzed.

The analysis of the previous research and the problem statement. Under the modern conditions there is a necessity for development of heat models for the analy- sis of IG operation [2]. During the choice of the heat model it is necessary to take into account the conditions of the induction machine operation [3-5]. The analysis of literature $[1,2]$ revealed that the thermal processes in IG are essentially influenced by steel losses. The method of thermal equivalent circuits is widely used for thermal calculations of electric machines in the solution of general problems of heating.

Losses dependences on the squared frequency and voltage are used as the basis for the classical methods of steel losses calculation [6, 7]. Moreover, it is shown in [8] that at high saturation of the magnetic system an abnormal increase of steel losses can be observed. This increase is much bigger than the values calculated by the conventional methods.

Usually, in induction machine thermal models the steel losses under the steady-state condition are not taken into consideration due to their small values. Taking into account the steel losses as a value proportional to the value of squared magnetic induction [9] results in a considerable error as such a relation is only true for an unsaturated magnetic circuit. Steel losses, having achieved rather high values, essentially influence the process of IG windings heating. That is why their neglect causes noticeable errors in determination of IG thermal state and is often inadmissible.

(C) V. Chenchevoi, Iu. Romashykhin, Zh. Romashykhina, Atef S. Al-Mashakbeh 
As a consequence, when dynamic thermal processes developing unequally at different degrees of magnetic system saturation are analyzed, there appears a necessity for a specified taking into account the steel losses in a heat model. So, the research of thermal transient processes in IG with capacitor self-excitation at the magnetic system high saturation is of both theoretical and practical interest.

Purpose of the paper. Working out the methods for assessment of the thermal operating modes of AES with IG.

Material and results of research. For the specified verification of IG element heating the non-stationary thermal processes are researched taking into account the real distribution of temperature and thermal flows in the machine. A three-mass mathematical model of an induction machine is analyzed in the paper. Apart from the stator and rotor windings the influence of the stator steel is taken into consideration in the model. However, in the analysis it is assumed that every active element represents a homogeneous body with an infinitely high internal thermal conductivity.

An induction motor (IM) is used as an IG. An IG thermal equivalent circuit is shown in Fig. 1. In accordance with the diagram, body 1 (stator winding) is characterized by heat capacity $C_{1}$ and is connected with the third body 3 (stator steel) by thermal conductivity $\Lambda_{13}$. Losses $\Delta P_{1}$ are allocated in body 1. Analogously, body 2 (rotor) is characterized by heat capacity $C_{2}$, is connected with body 3 by thermal conductivity $\Lambda_{23}$. Losses $\Delta P_{2}$ are allocated in body 2 . In its turn, body 3 is characterized by heat capacity $C_{3}$ and is connected with the environment by thermal conductivity $\Lambda_{3}$. Losses $\Delta P_{3}$ are allocated in body 3 .

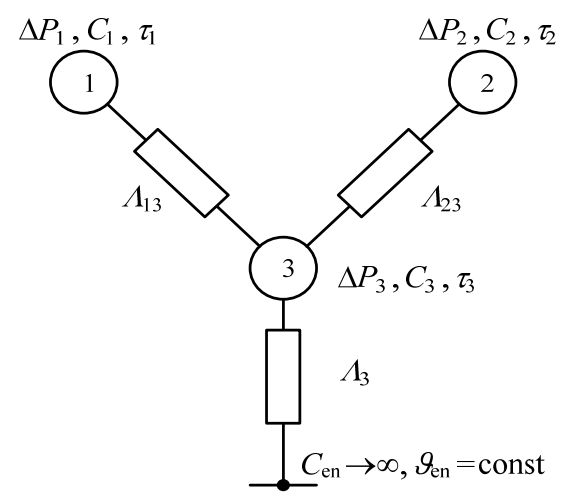

Fig. 1. Thermal diagram of an induction motor as a system of three bodies:

1 - stator winding; 2 - rotor; 3 - stator steel

The following designations are adopted in Fig. 1: $\tau_{1}, \tau_{2}, \tau_{3}$ - excess of the temperature of the stator winding, rotor and IM steel, respectively; $\vartheta_{\text {en }}-$ ambient temperature; $C_{\mathrm{en}}-$ environment heat capacity.

According to $[1,2]$, the heat balance equations for IM each body are presented in the form:

$$
\left\{\begin{aligned}
\Delta P_{1}= & C_{1} \frac{\mathrm{d} \tau_{1}}{\mathrm{~d} t}+\Lambda_{13}\left(\tau_{1}-\tau_{3}\right) ; \\
\Delta P_{2}= & C_{2} \frac{\mathrm{d} \tau_{2}}{\mathrm{~d} t}+\Lambda_{23}\left(\tau_{2}-\tau_{3}\right) ; \\
\Delta P_{3}= & C_{3} \frac{\mathrm{d} \tau_{3}}{\mathrm{~d} t}+\Lambda_{13}\left(\tau_{3}-\tau_{1}\right)+ \\
& +\Lambda_{23}\left(\tau_{3}-\tau_{2}\right)+\Lambda_{3} \tau_{3},
\end{aligned}\right.
$$

where the stator winding active power losses at the winding temperature $\theta_{1}$ :

$$
\Delta P_{1}=3 R_{\mathrm{s}} I_{\mathrm{s}}^{2}
$$

where $I_{\mathrm{s}}$ - active value of the stator current; $R_{\mathrm{s}}-$ resistive impedance of the stator winding; rotor winding active power losses at the rotor temperature $\theta_{2}$ :

$$
\Delta P_{2}=3 R_{\mathrm{r}} I_{\mathrm{r}}^{2}
$$

where $I_{\mathrm{r}}$ - active value of the rotor current; $R_{\mathrm{r}}-$ resistive impedance of the rotor winding.

The stator steel losses are caused by the hysteresis and eddy-currents in the stator core [7, 9].

According to the conventional method, the steel losses are determined by expression:

$$
\Delta P_{3}=\Delta P_{\text {st }}=\Delta P_{\text {st.r }}\left(\frac{U_{1}}{U_{1 \mathrm{r}}}\right)^{2},
$$

where $\Delta P_{\text {st.r }}$ - active power steel losses at rated voltage; $U_{1}-$ voltage current value; $U_{1 \mathrm{r}}-$ rated phase voltage.

During the analysis of steel magnetization reversal processes a dependence for the calculation of steel losses under the condition of magnetic system saturation was found:

$$
\Delta P_{3}=\Delta P_{\mathrm{st}}\left(I_{\mu}\right)=\frac{\xi}{\left(\frac{\mathrm{d} E\left(I_{\mu}\right)}{\mathrm{d} I_{\mu}}\right)}\left(E\left(I_{\mu}\right)\right)^{2},
$$

where $E\left(I_{\mu}\right)$ - electromotive force active value dependence on IM magnetization current active value $I_{\mu}$; $\xi$-coefficient depending on the material parameters.

Expression (5) demonstrates that at the nonsaturation section of the magnetization curve the electromotive force changes by the linear law, i.e. $\mathrm{d} E\left(I_{\mu}\right) / \mathrm{d} I_{\mu} \rightarrow$ const. In this case the equation takes the form analogous to Steinmetz equation [10]. When IM operates in the saturation mode, the velocity of electromotive force intensification decreases, i.e. $\mathrm{d} E\left(I_{\mu}\right) / \mathrm{d} I_{\mu} \rightarrow 0$. In this case there occurs a sharp growth of steel losses caused by lagging.

IM 4A90L4U3 was used in the analysis to research the thermal processes. The IM parameters are given in Table 1. The thermal condition parameters are given in Table 2.

Table 1

Parameters of 4A90L4U3 induction motor

\begin{tabular}{|l|c|}
\hline Parameter & Value \\
\hline Rated power, $\mathrm{kW}$ & 2.2 \\
\hline Rated voltage, V & 220 \\
\hline Stator rated current, A & 5 \\
\hline Efficiency & 0.8 \\
\hline Rated slid & 0.051 \\
\hline Stator resistive impedance, Ohm & 4.15 \\
\hline Stator inductive reactance, Ohm & 3.218 \\
\hline Rotor reduced resistive impedance, Ohm & 2.629 \\
\hline Rotor reduced inductive reactance, Ohm & 5.697 \\
\hline Magnetization circuit inductive reactance, Ohm & 92.03 \\
\hline
\end{tabular}


Table 2

Thermal condition parameters of 4A90L4U3 induction motor

\begin{tabular}{|c|c|}
\hline Thermal conductivities, $\mathrm{W} /{ }^{\circ} \mathrm{C}$ & 10.5707 \\
$\Lambda_{13}$ & 2.7648 \\
$\Lambda_{23}$ & 13.9969 \\
$\Lambda_{3}$ & \\
\hline Thermal capacities, $\mathrm{J} /{ }^{\circ} \mathrm{C}$ & 726.1 \\
stator winding $C_{1}$ & 3260 \\
rotor $C_{2}$ & 9623 \\
stator steel $C_{3}$ & 403 \\
\hline Stator rated temperature $\theta_{1 \mathrm{r}}, \mathrm{K}$ & \\
\hline
\end{tabular}

As a result of using the conventional method and the method for losses determination in a highly-saturated mode the IG rotor winding temperature excess curves were obtained (Fig. 2).

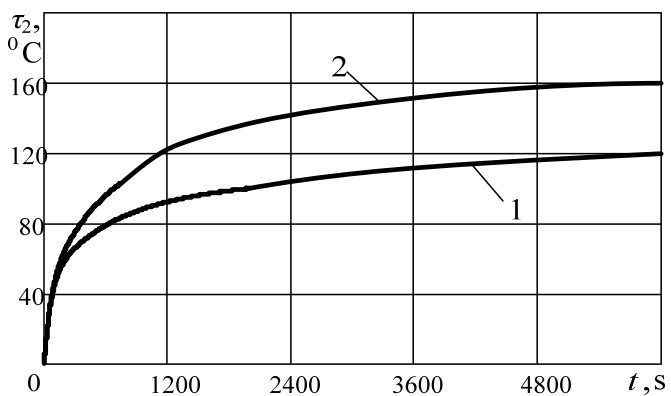

Fig. 2. Rotor temperature excess curve at different methods of steel losses calculation:

1 - with the use of the conventional method (based on expression (4)); 2 - based on expression (5)

The analysis of the presented dependences revealed that IG unit heating rates essentially differ at different methods of steel losses calculation. So, the windings temperature at the conventional method of steel losses account is considerably lower than with the use of the method for steel losses determination in a highly-saturated mode.

A thermal imager was used for verification of the adequacy of the thermal model. The thermogram of IG operation at self-excitation is presented in Fig. 3. It is seen in the figure that IG rotor windings heats up to the temperature of $148.7^{\circ} \mathrm{C}$. The results of comparison of the experiment and modeling (Fig. 2) revealed that the calculated excess of temperature with the use of expression (5) is $158{ }^{\circ} \mathrm{C}$. It suggests the conclusion that the proposed approach is adequate. The analysis of the obtained results revealed that the stator end windings are the most heated IG parts.

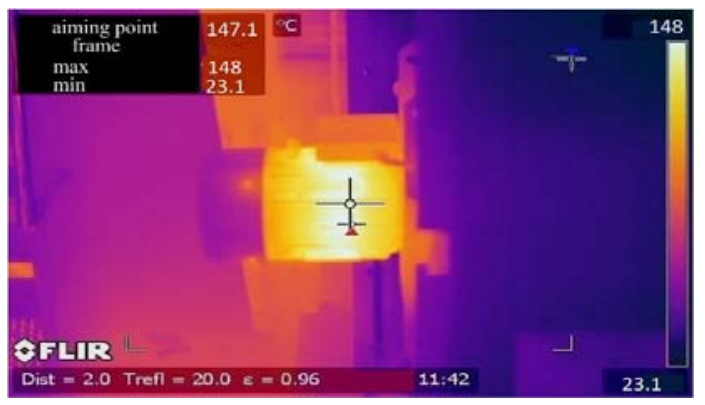

Fig. 3. A thermogram of the induction generator

\section{Conclusions.}

Steel losses influence on the IG thermal characteristics at high saturation of the magnetic system has been researched in the paper. It enables determination of temperature excess at particular units of the generator.

The developed heat model makes it possible to calculate maximal current temperatures in different parts of the motor with sufficient accuracy. The mathematical model allows determination of temperature at IG units that are inaccessible for direct measurement. The proposed heat model can be used at IG monitoring with the aim of forecasting their resource.

\section{REFERENCES}

1. Qiu Y., Zhang W., Cao M., Feng Y., Infield D. An ElectroThermal Analysis of a Variable-Speed Doubly-Fed Induction Generator in a Wind Turbine, Energies, 2015, vol.8, no.5, pp. 3386-3402. doi: 10.3390/en8053386.

2. Hodgins N., Mueller M.A, Tease W.K., Staton D. Thermal model of an induction generator in oscillating water column wave energy converter. 5th IET International Conference on Power Electronics, Machines and Drives (PEMD 2010), 2010. doi: $10.1049 /$ cp.2010.0020.

3. Zagirnyak M., Romashykhina Zh., Kalinov A. Diagnostic signs of induction motor broken rotor bars in electromotive force signal. 17th International Conference Computational Problems of Electrical Engineering (CPEE), 2016. doi: 10.1109/CPEE.2016.7738722.

4. Rodkin D.I., Romashihin Y.V. Rationale for settlement circuit for induction motors. Tekhnichna Elektrodynamika, 2012, no.2, pp. 89-90. (Rus).

5. Zagirnyak M., Rodkin D., Romashykhin Iu., Rudenko N., Chenchevoi V. Identification of nonlinearities of induction motor equivalent circuits with the use of the instantaneous power method, 17th International Conference Computational Problems of Electrical Engineering (CPEE), 2016. doi: 10.1109/CPEE.2016.7738721. 6. Rygal R., Moses A.J., Derebasi N., Schneider J., Schoppa A., Influence of cutting stress on magnetic field and flux density distribution in non-oriented electrical steels, Journal of Magnetism and Magnetic Materials, 2000, vol.215-216, pp. 687-689. doi: 10.1016/S0304-8853(00)00259-6.

7. Zidarič B., Zagirnyak M., Lenasi K., Miljavec D. Hysteresis losses in soft magnetic composite materials. COMPEL - The international journal for computation and mathematics in electrical and electronic engineering, 2006, vol.25, no.1, pp. 157-168. doi: 10.1108/03321640610634416.

8. Reinert J., Brockmeyer A., De Doncker R.W. Calculation of losses in ferro- and ferrimagnetic materials based on the modified Steinmetz equation. Conference Record of the 1999 IEEE Industry Applications Conference. Thirty-Forth IAS Annual Meeting (Cat. No.99CH36370). doi: 10.1109/IAS.1999.806023.

9. Maga D., Zagirnyak M., Miljavec D. Additional losses in permanent magnet brushless machines. Proceedings of 14th International Power Electronics and Motion Control Conference EPEPEMC 2010, 2010. doi: 10.1109/EPEPEMC.2010.5606520.

10. Steinmetz C. On the law of hysteresis. Proceedings of the IEEE, 1984, vol.72, iss.2, pp. 197-221. doi: 10.1109/PROC.1984.12842.

Received 05.06.2017

Vladimir Chenchevoi ${ }^{1}$, Candidate of Technical Science,

Iurii Romashykhin ${ }^{1}$, Candidate of Technical Science,

Zhanna Romashykhina ${ }^{1}$, Candidate of Technical Science,

Atef S. Al-Mashakbeh ${ }^{2}$, Candidate of Technical Science,

${ }^{1}$ Kremenchuk Mykhailo Ostrohradskyi National University,

20, Pershotravneva Str., Kremenchuk, Poltava region, 39600, Ukraine, phone +38 0982723441 ,

e-mail: vladchen.86@gmail.com, romashykhin.iurii@gmail.com, romashykhina.zhanna@gmail.com

${ }^{2}$ Tafila Technical University,

Et Tafila New Hauway Str., 179, Tafila, Et Tafila, 66110, Jordan, phone 00962772075700, e-mail: dr.atef_almashakbeh@yahoo.com

How to cite this article:

Chenchevoi V., Romashykhin Iu., Romashykhina Zh., Al-Mashakbeh Atef S. Analysis of the special features of the thermal process in an induction generator at high saturation of the magnetic system. Electrical engineering \& electromechanics, 2017, no.3, pp. 16-18. doi: 10.20998/2074-272X.2017.3.02. 